\title{
Exploring Relationship between Value- and Life-orientation and Job Satisfaction
}

\author{
Lynette Louw: Department of Management, Rhodes University \\ Claude-Hélène Mayer: Department of Management, Rhodes University \\ Jeremy Baxter: Department of Statistics, Rhodes University
}

\begin{abstract}
Purpose/objective: The purpose of this article is to investigate the relationship between value- and life-orientation and job satisfaction, as well as determining the influence of gender, age and cultural group within the selected South African organisational context.
\end{abstract}

Problem investigated: The success of a diverse organisation in a complex globalised world is largely dependent on the values of managers, their life-orientation and their level of job satisfaction. Managers and employees, in a multicultural and diverse South African organisational context, need to be aware of and manage their similarities and differences in these aspects to contribute to overall organisational success.

Design and/or research methodology and/or approach: In this exploratory research, use is made of a quantitative perspective in the positivist research paradigm. Value-orientations of managers $(N=30)$ at a selected parastatal organisation in the Eastern Cape Province in South Africa were measured by making use of the Schwartz Value Survey (SVS) (Schwartz, 1992,1994); life-orientation, also referred to as Sense of Coherence (SOC), was assessed by using Antonovsky's (1997) Life Orientation Questionnaire as well as job satisfaction (JS) using Smith, Kendall and Hulin's (1969)'s Job Descriptive Index. Data were analysed using the R statistical software package (R Development Core Team, 2010). Each of the three research instruments (SVS, SOC \& JS) considered in this study were used to calculate descriptive statistics and univariate statistical methodologies were used to test the various hypotheses.

Findings and/or implementations: In terms of value-orientation, the value of benevolence (preservation and enhancement of the welfare of others) was scored the highest by the managers, and a significant difference was found in the average value scale score of stimulation (excitement, novelty, and challenge in life) and age. The findings with regard to lifeorientation indicated that manageability and comprehensibility were more important to managers than meaningfulness. A significant difference was found between meaningfulness and gender. In terms of cultural groups, significant differences between the average African and Indian and White and Indian meaningfulness scale scores were found. With regard to job satisfaction, there was generally a highly satisfied response to co-workers and a moderate satisfaction with work and supervisors. However, respondents were dissatisfied with pay and promotion. Additionally, significant relationships were found between some of the life- and value-orientation scales; the value-orientation and job satisfaction scales; and life-values and job satisfaction scales.

Originality and/or value of research: This paper is based on original research and contributes to a better understanding of the relationship between value- and life-orientation and job satisfaction in a South African organisational context, as well as contributing towards empirical evidence of such relationships. Even though there seems to be a theoretical relationship between value and life-orientation, no empirical evidence to support this assertion has been found, highlighting the importance of this exploratory research. It has also been found that value-orientation is related to job satisfaction, and that life-orientation is related to job satisfaction. However, the theoretical link between life-orientation and job satisfaction has received relatively little research attention in South Africa, and empirical evidence to support this within a South African perspective is required. The findings of this exploratory research will also be of value to the selected organisation, and will provide information that can be used to develop intervention strategies.

Conclusion: Managers in this parastatal highly value socially orientated values, indicating a strong in-group, mutual support and a concern for society, reflecting the vision and nature of the organisation. Referring to life-orientation, a stronger sense of meaningfulness could positively influence organisational meaning and managerial satisfaction. Greater job satisfaction could increase the value of life-orientation for managers. In terms of the relationship between value- and life-orientation, negative and positive linear relationships were found. Negative linear relationships were found between value-orientation and job satisfaction, while a positive linear relationship was found between life-orientation and job satisfaction.

Keywords: Social values, salutogenesis, sense of coherence (SOC), job satisfaction, health management, cross-cultural management, South Africa, parastatal organisation 


\section{INTRODUCTION AND THEORETICAL BACKGROUND}

In the multicultural and diverse South African organisational context, managers and employees need to be aware of and to manage their similarities and differences in value orientation, life-orientation, and their levels of job satisfaction, to contribute to overall organisational effectiveness.

Values can be viewed as "desirable trans-situational goals, varying in importance, that serve as guiding principles in the life of a person or other social entity" (Schwartz, 1994:24). As such, values are common goals and serve the interest of a particular social entity, such as an organisation and motivate groups and teams by providing direction and emotional intensity and are guiding principles which serve as standards for judging and justifying action (Schwartz, 1994:24). Values are acquired both through socialisation with dominant group values and through the unique learning experience of individuals. Through socialisation, values then become a socio-cultural concept of individuals, groups or societies.

Value-orientations are patterns of thoughts and actions (Kluckhohn \& Stroedbeck, 1961: 4) which are important aspects of organisations and of group membership. Agreement on values in an organisation is subject to change over time and determined by group members' ability to accept the values of others (Burton, 1990: 213). Values are often un-reflected and unconscious until conflict occurs, and the conflicting parties realise that their conflict derives from differences in patterns of thoughts and actions. Values are essentially dialectic and contradictory and can lead to conflict and be reflected in incompatible and competing goals (Berkel, 2005: 2). Research on value-orientation has become important in the field of management, for example, with research focusing on organisational culture, identity and organisational conflict (Mayer, 2008; Schwartz \& Bardi, 2001). Values influence the organisational context with regard to both processes and organisational culture (Gandal, Roccas, Sagiv \& Wrzesniewski, 2005; Smith, Peterson \& Schwartz, 2002). Even though research on values in the African region has been increasing, Sub-Saharan Africa is still under-represented in organisational value research (Jackson, 2011 and Mayer \& Louw, 2009). Value-orientations by Schwartz (1992; 1994) (SVS), which form the basis of this research, are defined and explained in Table 1. These value-orientations have been validated by previous research teams (Schwartz \& Bardi, 2001and Spini, 2003).

Table 1: Schwartz's value definitions

\begin{tabular}{|l|l|}
\hline DEFINITION OF VALUES & EXEMPLARY VALUES \\
\hline $\begin{array}{l}\text { Power: Social status and prestige, control or } \\
\text { dominance over people and resources }\end{array}$ & Social power, authority and wealth \\
\hline $\begin{array}{l}\text { Achievement: Personal success through } \\
\text { demonstrating competence according to social } \\
\text { standards }\end{array}$ & Successful, capable, ambitious \\
\hline $\begin{array}{l}\text { Hedonism: Pleasure and sensuous gratification for } \\
\text { oneself }\end{array}$ & Pleasure, enjoying life \\
\hline Stimulation: Excitement, novelty, and challenge in life & Daring, varied life, exciting life \\
\hline $\begin{array}{l}\text { Self-direction: Independent thought and action- } \\
\text { choosing, creating, exploring }\end{array}$ & Creativity, curious, freedom \\
\hline $\begin{array}{l}\text { Universalism: Understanding, appreciation, tolerance } \\
\text { and protection for the welfare of all people and for } \\
\text { nature }\end{array}$ & $\begin{array}{l}\text { Broad-minded, social } \\
\text { justice, equality }\end{array}$ \\
\hline $\begin{array}{l}\text { Benevolence: Preservation and enhancement of the } \\
\text { welfare of people with whom one is in frequent } \\
\text { personal contact }\end{array}$ & Helpful, honest, forgiving \\
\hline $\begin{array}{l}\text { Tradition: Respect, commitment and acceptance of } \\
\text { the customs and ideas that traditional culture or } \\
\text { religion provide }\end{array}$ & $\begin{array}{l}\text { Humble, devout, accepting my "portion in } \\
\text { life" }\end{array}$ \\
\hline $\begin{array}{l}\text { Conformity: Restraint of actions, inclinations, and } \\
\text { impulses likely to upset or harm others and violate } \\
\text { social expectations or norms }\end{array}$ & $\begin{array}{l}\text { Politeness, obedience } \\
\text { Honouring parents and elders }\end{array}$ \\
\hline $\begin{array}{l}\text { Security: Safety, harmony and stability of society, of } \\
\text { differences and of self. }\end{array}$ & $\begin{array}{l}\text { National security } \\
\text { Social order, cleanliness }\end{array}$ \\
\hline
\end{tabular}

Source: Schwartz (1994: 22) 
On the other hand, Antonovsky's (1979) perspective on "life orientation" is largely determined by a single psychological factor, which is the general attitude towards the world and one's own life. Life orientation explains how people feel, how they behave and cope with stress, and how they keep healthy (Blättner, 2007). This described general attitude towards life and the world is also referred to by Antonovsky (1979) as a "Sense of Coherence". A Sense of Coherence (SOC) is explained in terms of a sense of comprehensibility; sense of manageability; and sense of meaningfulness (Antonovsky, 1979). A sense of comprehensibility describes the expectation or the ability of a person to process familiar and unfamiliar stimuli as ordered, consistent, structured information, and not as chaotic, random, accidental and inexplicable. To make sense of the world, a person with this life-orientation prefers classified, categorised and structured information. As mentioned previously, a sense of manageability indicates confidence in the perception that resources are at one's disposal, are "adequate to meet the demands posed by the stimuli" (Antonovsky, 1987:17) and can be developed through the experience of being able to effectively use one's own resources. The experience of manageability can also derive from the assumption that other people or a higher power, such as God, will help to overcome life's challenges. A person with a high sense of manageability is convinced that challenges can be resolved easily. A sense of meaningfulness is described as "the extent to which one feels that life makes sense emotionally, that at least some of the problems and demands posed by living are worth investing energy in, are worthy of commitment and engagement, are challenges that are 'welcome' rather than burdens that one would much rather do without" (Antonovsky, 1987:18). Meaningfulness is fostered by the assumption that life makes sense and that a person's experience contributes towards a meaningful life. The sense of meaningfulness is considered to be the most important component in a person's life, because without meaningfulness, life is experienced as a burden (Bengel, Strittmatter \& Willmann, 2001: 26).

As referred to previously, keeping healthy is also closely related to life-orientation and the ability to cope with stress. The World Health Organisation (2002) defined health as "physical, mental and social well-being, not merely the absence of disease or infirmity". Health has become a social category in which mental health is conceptualized as a state of well-being in which the individual realizes his or her own ability to cope with normal stresses of life and adopt and maintain healthy lifestyles (WHO, 2007). Thus, health has become a physical, but also a socio-cultural phenomenon of individual constructs. It is identical with "the subjective well-being and the health-oriented behaviour of a person" (Bengel, et al., 2001:15).

The extent of how well developed "life-orientation" is in an individual impacts on the individual and his/her work (Strümpfer, 1990). Individuals with a well-developed SOC can maintain personal balance despite high levels of stress (Howard, 2008). They can make cognitive sense of a stressful situation and of the workplace organisational culture. They also perceive stimulation in the workplace as clear, ordered, structured, consistent and predictable, and can therefore deal with challenging situations. Managers with a high SOC usually feel that they can deal with the workplace challenges by activating personal or collective resources (Mayer, Louw \& Louw, 2010). They also feel that their work and life make sense and that work demands are welcome challenges in which they like to invest their energy.

Lastly, the importance of job satisfaction to human beings is a phenomenon that has been widely studied and remains a popular research area in management and industrial psychology (Cranny, Smith, and Stone, 1992; Fisher 1998). The reason for the popularity of the subject is not hard to explain. "Most individuals spend a large part of their working lives at work, so that an understanding of factors involved in job satisfaction is relevant to improving their well being and hence is an important aspect of their lives" (Gruneberg, 1979:1). The popularity of this field of study can also be attributed to the relevance of job satisfaction to the physical and mental well-being of employees, and in one form or another it has been related to such variables as turnover, job performance, absenteeism and productivity, all which do impact on the profitability of organisations (Fisher, 1998: 23).

Job satisfaction can be explained as a pleasurable or positive emotional state, resulting from the appraisal of one's job and job experience (Alessandri, Vecchione, Tisak, Deiana, Caria \& Caprara, 2012). For many years the dominant view of job satisfaction was situational, with interventions aimed at increasing job satisfaction by influencing job characteristics (Houghton \& Jinkerson, 2007:45). Job characteristics such as pay, work, and opportunity for promotion, supervision and co-workers, illustrate the multidimensional aspect of job satisfaction. Work itself, supervision and co-workers are regarded 
as being intrinsic rewards, while pay and promotional opportunities are extrinsic rewards associated with job characteristics and satisfaction. Even though job satisfaction is mostly measured as a cognitive evaluation of the multidimensional aspects of job characteristics, the viewpoint of describing and measuring job satisfaction as an attitude has gained eminence (Fisher 1998: 3; Houghton \& Jinkerson, 2007:45). An "attitude" is usually described as consisting of two aspects namely, effective and cognitive (Alarcon \& Lyons, 2011:465). The affective aspect refers to emotions and feelings while the cognitive attitude refers to belief and judgmental aspects (Fisher, 1998:3). Consistent with this viewpoint, job satisfaction has been cited as being an emotional response (Fisher, 1998:3) to one's job. Houghton and Jinkerson (2007:45) argue that an affective disposition is "a key determinant of subjective well-being" which is "reciprocally related to job satisfaction," while Fisher (1998: 23) found that overall job satisfaction is correlated with moods and emotions experienced at work, the latter representing a sense of quality of work-life. Job satisfaction, related to life-orientation, can be explained as a pleasurable or positive emotional state, resulting from the appraisal of one's job or job experience (Alessandri et al, 2012), while the cognitive attitude towards job satisfaction would be more associated with an individual's value-orientation. Research has shown that both the effective and cognitive aspects are important contributors to an overall attitude toward one's job and linked to behaviour (Fisher, 1998:3). The definition of job satisfaction by Smith, Kendall and Hulin (1975: 12) provides an appropriate summary to the discussion in this section; job satisfaction is "the perceived characteristics of the job in relation to an individual's frames of reference. Alternatives available in given situations, expectations and experience play important roles in providing the relevant frame of reference."

The relationship between value- and life-orientation and job satisfaction will be explored in the next section.

\section{The relationship between value- and life-orientation and job satisfaction}

Value preferences and their importance vary in different social and organisational areas (Gandal et al., 2005:1227). Values are strongly predictive of reliance on sources of guidance (Smith et al., 2002), particularly vertical relationships within organisations, and require great sensitivity towards the cultural contexts in which they occur. Value-orientation seems to influence the meaning of work and the organisational setting (Ros, Schwartz \& Surkiss, 1999; Schwartz, 1999) and seem to be important with regard to life orientation, SOC, and its development. In terms of life-orientation, previous research on values has shown that as people grow older, they tend to become more embedded in life-orientated networks, committed to habitual patterns, and less exposed to arousing and exciting changes and challenges (Glen, 1974). This implies that they are less open to stimulating and innovative challenges (Schwartz, 2005).

Antonovsky (1993:13) does not relate life orientation to any particular value-orientation from Schwartz's value survey, but rather correlates SOC with specific values such as autonomy, creativity, freedom, warmth, equality, dignity and respect. It should be noted that SOC can be developed in different socio-cultural surroundings which do not necessarily accept or promote the aforementioned values. Despite this, Sagy and Antonovsky (2000) emphasise that a stable value system promotes a development of a high level of life-orientation, and different experiences and value priorities exist across cultures to develop life-orientation (Mayer, 2011:343). While Lindström and Eriksson (2006) add that values and value systems influence life-orientation (SOC), no empirical evidence has been found to support this assertion.

Research on value-orientation and job satisfaction has found that values influence job satisfaction (e.g. Verplanken, 2004). It is suggested that people who attach a high value to human relation values show high levels of job satisfaction in general. Eliason, Guse and Gottlieb (2000) have found that individuals with high values in Benevolence experience a higher job satisfaction than others. This has been confirmed by Arciniega and González (2003:6) who assert that "individuals who assign high priority to the high-order value self-transcendence tend to be more satisfied with their jobs, because these subjects pay less attention to evaluation of personal costs and benefits when processing social information."

Studies have shown that life-orientation (SOC) is positively related to job satisfaction (JS) (Rothmann, 2001; Strümpfer and de Bruin, 2009:1; Strümpfer, Danana, Gouws and Viviers, 1998). SOC influences the ability to mobilise and generate social resources in the workplace, the stronger the 
SOC, the easier it is to mobilise different types of resources. SOC is viewed as having a significant effect on how managers perceive the demands and resources at work (Fourie, Rothmann \& Van de Vijver, 2008). Individuals with a low SOC tend to be motivated by extrinsic resources, such as pay, while those with a strong SOC seem to be motivated by the "intrinsic nature of the work" which they perceive as engaging and satisfying (Muller \& Rothmann, 2009:3). Strümpfer and de Bruin (2009:1) emphasise that the relationship between SOC and work "is likely to be bi-directional and work experiences could also, over time, strengthen or weaken the SOC." However, the theoretical link between life-orientation and job satisfaction has received relatively little research attention in South Africa. In the meta-analysis of South African data, Strümpfer and de Bruin (2009) have confirmed their hypothesis that SOC is positively correlated with job satisfaction. Although SOC does not contain explicitly stated work-related items, the strength of relation between it and job satisfaction is surprisingly high. Strümpfer and de Bruin (2009:3) point out that the "result is consistent with previous studies that found that personality variables have an effect on job satisfaction", such as Judge, Locke, Durham and Kluger (1998). Research pertaining to the relationship between job satisfaction and personality variables has shown that people with stable positive core self-evaluation are more satisfied with their jobs than people with negative core self-evaluation (Judge \& Hurst, 2007). There is also a relationship between job satisfaction and life-orientation associated with subjective well-being and health (Houghton \& Junkerson, 2007) and moods and emotions experienced at work (Fisher, 1998:23). As previously mentioned, it is likely that people with a high SOC will experience high job satisfaction. This could be attributed primarily to them viewing their tasks as challenges which they tend to structuralise and search for appropriate resources to cope with (Antonovsky, 1987) and better cope with stress (Bengel et al., 2001).

In the following sections, the research purpose, objectives and hypotheses will be introduced, and an overview of the research methodology will be given. Finally, findings will be presented, together with conclusions and recommendations.

\section{PURPOSE AND OBJECTIVES}

This article aims at contributing to a better understanding of the relationships between value- and lifeorientations and job satisfaction amongst managers at a selected organisation, as well as contributing towards empirical evidence of such relationships. Even though there seems to be a theoretical relationship between value and life-orientation (Lindström \& Eriksson, 2006 and Sagy \& Antonovsky, 2000), no empirical evidence to support this assertion has been found, highlighting the importance of this exploratory research. It has also been found that value-orientation influences job satisfaction (e.g. Arciniega and González, 2003:6; Eliason et al., 2000 and Verplanken, 2004) and that life-orientation is related to job satisfaction (Strümpfer \& de Bruin 2009:1). Unique to this research is the contribution to the limited previous empirical research supporting the relationships between value- and lifeorientation, between value-orientation and job satisfaction, and between life-orientation and job satisfaction. In addition, the findings of this exploratory research will be of value to the selected organisation and provide information that can be used to develop intervention strategies such as training courses, workshops and managerial coaching for managers and employees, thereby enhancing the effective management of the organisation.

Consequently, the purpose of this article is to investigate the relationship between value-orientation, life-orientation and job satisfaction in a South African organisational context, thereby contributing towards filling the void of the empirical research base in this regard. It is also assumed that the research findings will be influenced by variables of gender, age and cultural group within the selected South African organisational context. To achieve the purpose of this study, the primary objective is to understand the profile and nature of the relationship between managerial value-orientation, lifeorientation and job satisfaction in the selected organisation. To give effect to the primary objective, the secondary objectives of this study, are to:

- determine the profiles of value- and life-orientations and job satisfaction amongst managers in the selected organisation;

- determine whether selected biographical variables such as gender, age and cultural group influence the value- and life-orientations and job satisfaction of the managers in the selected organisation; 
- establish the nature of the relationship between the scales of value- and life-orientations and job satisfaction; and

- establish the nature of the relationship between value- and life-orientations; value-orientations and job satisfaction; and life-orientation and job satisfaction; among managers in the selected organisation.

To achieve the secondary objectives of this study, the following hypotheses have been stated:

$\mathrm{H}^{1.1}$ : There are statistically significant differences in the average scores of the value-orientation scales and selected biographical variables, such as gender $\mathrm{H}^{1.1 \mathrm{a}}$, age $\mathrm{H}^{1.16}$ and cultural group $\mathrm{H}^{1.1 \mathrm{c}}$.

$\mathrm{H}^{1.2}$ : There are statistically significant differences in the average scores of the life-orientation scales and selected biographical variables, such as gender $\mathrm{H}^{1.2 a}$, age $\mathrm{H}^{1.2 b}$ and cultural group $\mathrm{H}^{1.2 \mathrm{c}}$.

$\mathrm{H}^{1.3}$ : There are statistically significant differences in the average scores of the job satisfaction scales and selected biographical variables, such as gender $\mathrm{H}^{1.3 a}$, age $\mathrm{H}^{1.3 \mathrm{~b}}$ and cultural group $\mathrm{H}^{1.3 \mathrm{c}}$.

$\mathrm{H}^{2}$ : There are statistically significant linear relationships between the scales of the: value-orientation instrument $\mathrm{H}^{2.1}$; life-orientation instrument $\mathrm{H}^{2.2}$; and job satisfaction instrument $\mathrm{H}^{2.3}$.

$\mathrm{H}^{3}$ : There are statistically significant linear relationships between the scales of the: value- and lifeorientation instruments $\mathrm{H}^{3.1}$; value-orientation and job satisfaction instruments $\mathrm{H}^{3.2}$; and lifeorientation and job satisfaction instruments $\mathrm{H}^{3.3}$.

\section{RESEARCH METHODOLOGY}

A positivistic research paradigm is most appropriate, given the nature of this exploratory study and the stated hypotheses. In this paradigm, explanation "consists of establishing casual relationships between the variables by establishing causal laws and linking them to deductive or integrated theory" (Collis \& Hussey, 2003: 53).

To give effect to the research objectives and to test the stated hypotheses, an empirical survey was conducted at a selected parastatal organisation in the Eastern Cape Province in South Africa. The research population included all the managers at the selected parastatal, amounting at the time to a total of 31 managers. A total of 30 respondents completed the research instruments with regard to value- and life-orientation and job satisfaction; the usable responses included: 26 responses for the value-orientation survey; 28 responses for the life-orientation survey; and 24 responses for the job satisfaction survey. The rationale for excluding unusable responses for each of the surveys will be given in the subsequent sections relevant to the research instruments.

\section{The research instruments and data collection}

The data was collected by means of following three research instruments, value-orientation was measured by the Schwartz Value Survey (SVS) (Schwartz, 1992,1994); life-orientation, also referred to as SOC, was assessed by using Antonovsky's (1997) Life Orientation Questionnaire; and job satisfaction (JS) using Smith, Kendall and Hulin's (1969) Job Descriptive Index. The self-administered questionnaires, which were administered during the course of a two-day strategic session held by the selected organisation, were voluntarily completed and inserted into a sealed box.

The Schwartz Value Survey (SVS) $(1992,1994)$ measured the personal values that were important in the life of individuals and consisted of 57 items. Respondents had to rate how important each value was as a guiding principle in their life. Use was made of a rating scale of 0 (the value is not at all important, it is not relevant as a guiding principle); 3 (the value is important); and 6 (the value is very important). In addition a rating of -1 would indicate values opposed to the guiding principles, while a rating of 7 would indicate a value of supreme importance as a guiding principle. A high value score represents strong values; low value scores represent weak values. By measuring the personal and collective values of an individual, the Schwartz Value Survey indicates the value priorities of a person. As mentioned previously, the values measured were: Benevolence, Conformity, Achievement, Universalism, Self direction, Security, Stimulation, Hedonism, Tradition and Power.

The Antonovsky (1997) Life Orientation Questionnaire (SOC) assessed different aspects of life and analysed life-orientations of individuals such as the scales of Manageability (10 questions), Comprehensibility (11 questions) and Meaningfulness (8 questions). These life-orientations also provided an indication of an individual's well-being and health. The questionnaire consisted of 29 , seven-point Likert-type questions to which the respondents had to respond. 
The Job Descriptive Index (JDI) (Smith et al. (1969) comprised five work facets of job satisfaction, namely Work (18 items), Pay (9 items), Supervision (18 items), Co-workers (18 items) and Promotion (9 items) opportunities. The 72 items consisted of short words or phrases. Respondents had to respond by placing a "Y" (yes) beside an item if it described the particular aspect of the job, an "N" (no) if it did not, and a "?" (not sure or not applicable) if they could not decide. Scoring of job satisfaction followed the instructions by Smith et al. (1969). For positive statements "Yes" = 3, "No" = 0 and "Not sure" $=1$. The scores were reversed, namely "Yes" = 0 , "No" = 3 and "Not sure" $=1$, for the negative statements.

\section{Data analysis}

These data were analysed using the $R$ statistical software package ( $R$ Development Core Team, 2010). Each of the three research instruments (SVS, SOC \& JS) considered in this study were used to calculate descriptive statistics, such as the mean and standard deviation, relating to valueorientations, life-orientation and job satisfaction scales. The multivariate nature of these data was considered in the choice of an appropriate approach for the data analysis. The numbers of observations in each cell were typically less than the number of data variables when considering using a MANOVA. Consideration of the Mahalanobis' distance indicated that there were multivariate outliers in this data set, which would lead to Type I or Type II errors (Rencher, 2002:198) in the MANOVA model(s). Some of the data variables were multicollinear with correlations above 0.7 . Some of the data variables did not have homogeneous variances. As a result of these concerns, the small size of this data set, and the exploratory nature of this study, univariate statistical methodologies were used to test the various hypotheses. Care should be taken when interpreting the results reported in this study owing to the inflated overall Type I error. To determine whether there were significant differences in the average scores for the value-orientations, life-orientation and job satisfaction scales and the influence of selected biographical variables such as gender, age and cultural group, suitable t-tests or one-way ANOVAs were used. Pearson's correlation coefficient and the associated t-test were used to assess the relationship and significance of the relationship between the scales of the valueorientations, life-orientation and job satisfaction instruments.

All the scales in the measuring instrument were subjected to Cronbach alpha coefficient analysis for reliability. To be reliable, measurement must be consistent between each individual surveyed across settings and at different times (Collis \& Hussey, 2003:58). Reliability is important as it indicates whether or not an instrument's measures are free from error, therefore yielding consistent results (Collis \& Hussey, 2003:58). However, because of the small number of respondents in this study, care was taken in the interpretation of the results of this study. "Validity" is the extent to which the survey information is relevant to the conclusion being drawn, and is sufficiently accurate and complete to support the conclusion (Collis \& Hussey, 2003). Owing to the sample size of this study, the validity of the research instruments was not determined, but a brief review of previous research pertaining to the reliability and validity of the measuring instruments used in this study will be given.

The reliability of the value-orientation (SVS) scales has been assessed through Cronbach alpha reliability coefficients for each value and in different cultures by other researchers (e.g. Arciniega \& Gonzalez, 2000, Sarros \& Santora, 2001).

Antonovsky (1997) indicated that the SOC scales yield internal reliability indices of between 0.78 and 0.93 , as reported in 26 different studies, and test-retest reliability indices of between 0.56 and 0.96 . Furthermore, Antonovsky (1993) reported a consistently high correlation coefficient ranging between 0.83 and 0.93 , indicating the internal consistency and reliability of the SOC scales. Others confirmed the internal consistency at 0.80 (Baloyi, 2000; Jackson \& Rothmann, 2001), and 0.91 (Lustig \& Strauser, 2002) and a high test-retest reliability of 0.90 (Cilliers \& Kossuth, 2004) and 0.93 at a 30-day interval (Frenz, Carey \& Jorgensen, 1990). Antonovsky (1993) reported construct validity varying between 0.38 and 0.72. Antonovsky (1993) and later Kivimaki, Feldt, Vahtera and Nurmi (2000) confirmed that the instrument has construct, content, face, consensual, predictive and criterion validity. The SOC instrument has been used in at least 33 languages in 32 countries all over the world, comprising both Western countries and countries such as Thailand, China, Japan, and South Africa. It seems to be a cross-culturally applicable instrument. The SOC scale has been validated for the South African context (Randall, 2007). South African studies on salutogenesis and SOC (see Strümpfer \& Wissing, 1998 for an overview) have, besides others, focused on SOC in work contexts (Du Buisson- 
Narsai, 2005; Lochner, 2000; Mayer \& Boness, 2009; Mayer et al., 2010; Pillay, 2008 and Rothmann, 2001).

Research conducted by Kinicki, McKee-Ryan, Schriesheim and Carson (2002:25, 26) stated that the Job Description Instrument (JDI) instrument had shown internal consistency reliability estimates that were moderately high, while Fisher (1998:16) and Kass, Vodanovich and Callender (2001: 321-322) confirmed the internal consistency of the five JDI scales with Cronbach alpha coefficients for each scale of 0.82 and above. According to Pennington and Riley (1991:22), this instrument is well documented as being valid and reliable, highly regarded, easy to complete and the most used research instrument in job satisfaction-related research. The latter is confirmed by Kinicki et al. (2002:15) who identified that the use of the Job Descriptive Index, as recorded in major industrialorganisational psychology journals between 1975 and 1999, amounted to 210 studies.

\section{Research ethics and limitations}

The research participants agreed to participate voluntarily by completing the self-administered questionnaires. To ensure anonymity, the respondents were requested to insert their responses into a sealed box. Confidentiality was guaranteed by the researcher, and maintained throughout the research process and upon the publication of research findings. The names and positions of the managers were therefore not linked with the content of the data, to ensure anonymity and confidentiality.

The limitation of this research is that it is based on one selected organisation with a limited number of respondents. It should be pointed out that the respondents represented management at the selected organisation. Considering the aforementioned, this research should be viewed as exploratory in nature. Despite this, other similar parastatals could benefit by drawing on the findings of this research.

\section{FINDINGS}

\section{Biographical information}

From the biographical information it was evident that the most prevalent age group was between the ages of $40-49(36.67 \%)$ and the majority of the respondents were male $(76.67 \%)$. Middle management comprised $43.33 \%$ of the sample, while lower management consisted of $40 \%$ and top management $13.33 \%$. Seventy-six percent of the respondents were religious and $70 \%$ were married. Forty-three per cent of the respondents were from the African cultural group, $36.67 \%$ from the White cultural group, $13.33 \%$ from Indian and $3.33 \%$ from the Coloured cultural group.

\section{Reliability of findings}

As a rule of thumb, Cronbach alpha coefficients of less than 0.50 are deemed to be unacceptable, those between 0.50 and 0.60 are regarded as sufficient, and those above 0.70 as acceptable (Nunally, 1978). Even though the generally accepted threshold for Cronbach alpha is 0.70 , this limit may be lowered to 0.60 in exploratory research (Nunnally, 1978; Robinson, Shaver \& Wrightsman, 1991).

In this research the Cronbach alpha coefficients for the value-orientation scales according to the Schwartz Value Survey (SVS) were acceptable for Conformity (0.7964), Benevolence (0.7404), SelfDirection (0.7986), Stimulation (0.7740), Hedonism (0.7329) and Achievement (0.7695); sufficient for Universalism (0.6628), Power (0.6385) and Security (0.5936); and unacceptable for Tradition (0.3653). The Cronbach alpha coefficients for the life-orientation scales according to the Antonovsky Life Orientation Questionnaire (SOC) were sufficient for Comprehensibility (0.6837), acceptable for Manageability $(0.7340)$ and good for Meaningfulness (0.8118). The Cronbach alpha coefficients for the job satisfaction scales according to the Job Descriptive Index (JDI) were acceptable for Work (0.7147); good for Supervision (0.9092), Co-Workers (0.8088), Pay (0.8530) and Promotion (0.8288).

\section{Value-orientation of managers}

The data were scored, and cleaned using the standard criteria described in Schwartz (2009), namely those subjects who had not tried to discriminate among their values, who had skipped too many items, or who had responded in ways suggesting deliberate misrepresentation. This resulted in the removal of four respondents. In the subsequent correlation analyses these data were corrected for individual 
differences in use of the response scale by computing the Mean RATing for the particular individual (MRAT) as per Schwartz (2009). The mean and standard deviation of the unscaled and the centred, MRAT, value-orientation (SVS) scale scores are shown Table 2.

Table 2: Value-orientation scales - Schwartz Value Survey (Schwartz 1992, 1994)

\begin{tabular}{|l|l|l|l|}
\hline $\begin{array}{l}\text { Value-orientation } \\
\text { (SVS scales) }\end{array}$ & Valid N & Unscaled Mean (SD) & MRAT: Mean (SD) \\
\hline Benevolence & 26 & $5.4692(0.8559)$ & $0.6358(0.6605)$ \\
\hline Conformity & 26 & $5.2981(1.0630)$ & $0.5743(0.7519)$ \\
\hline Achievement & 26 & $5.0192(1.1246)$ & $0.2680(0.6710)$ \\
\hline Universalism & 26 & $5.0288(0.9749)$ & $0.2567(0.6175)$ \\
\hline Self-Direction & 26 & $4.8769(1.2041)$ & $0.1863(0.7922)$ \\
\hline Security & 26 & $4.7115(0.9635)$ & $-0.0102(0.6360)$ \\
\hline Stimulation & 26 & $4.3718(1.6609)$ & $-0.4803(1.1380)$ \\
\hline Hedonism & 26 & $4.1603(1.5162)$ & $-0.6240(0.9305)$ \\
\hline Tradition & 26 & $4.1038(0.8766)$ & $-0.6516(0.8159)$ \\
\hline Power & 26 & $2.9006(1.3976)$ & $-1.7734(1.0182)$ \\
\hline
\end{tabular}

From Table 2 the scoring of the value scales are given in order of highest to lowest scores, with the highest score for Benevolence and the lowest score for Power. To compare the average scores for the scales of the SVS instrument, the centred scores were considered based on the Mean RATing as suggested by Schwartz (2009). These scales do not have equal population variances (Bartlett's Ksquared $=33.2513, \mathrm{df}=9, \mathrm{p}$-value $=0.0001$ ). These scales do not have equal medians (KruskalWallis chi-squared $=97.3148, \mathrm{df}=9, \mathrm{p}$-value $<2.2 \mathrm{e}-16$ ). Pairwise Wilcoxon Rank Sum Tests, using Holm's method to adjust the $p$-value for the multiple comparisons, showed significant differences in the average scores between Achievement and Power ( $p$.value $<0.001)$; Achievement and Tradition ( $p$ value $=0.0067)$; Benevolence and Hedonism ( $p$-value $=0.0003)$; Benevolence and Power ( $p$-value < $0.001)$; Benevolence and Security ( $p$-value $=0.0001)$; Benevolence and Stimulation ( $p$-value $=0.005)$; Benevolence and Tradition ( $p$-value $<0.001$ ); Conformity and Hedonism ( $p$-value $=0.0033$ ); Conformity and Power ( $p$-value $<0.001)$; Conformity and Security ( $p$-value $=0.0038$ ); Conformity and Stimulation $(p$-value $=0.039)$; Conformity and Tradition $(p$-value $=0.0003) ;$ Hedonism and Power $(p-$ value $=0.0038)$; Power and Security $(p$-value $<0.001)$; Power and Self Direction ( $p$-value $<0.001)$; Power and Stimulation $(p$-value $=0.0118)$; Power and Tradition $(p$-value $=0.0038)$; Power and Universalism ( $p$-value $<0.001$ ); Self Direction and Tradition ( $p$-value $=0.0417$ ) and Tradition and Universalism ( $p$-value $=0.0209$ ).

Separate Levene's tests indicated that these data provided insufficient evidence that the male and female populations had significantly different population variances. Separate t-tests were conducted on each value-orieintation scale, using separate estimates for the population variances. No significant differences were found between the average value-orientation scale scores for each gender, at the $5 \%$ level of significance: Benevolence $(t=-0.6533, \mathrm{df}=24, \mathrm{p}$-value $=0.5198)$, Conformity $(\mathrm{t}=-0.5563, \mathrm{df}=$ 24 , $\mathrm{p}$-value $=0.5831)$, Achievement $(\mathrm{t}=-0.0468, \mathrm{df}=24, \mathrm{p}$-value $=0.963)$, Universalism $(\mathrm{t}=-0.612$, $\mathrm{df}=24, \mathrm{p}$-value $=0.5463)$, Self Direction $(\mathrm{t}=0.9006, \mathrm{df}=24, \mathrm{p}$-value $=0.3768)$, Security $(\mathrm{t}=-0.2223$, $\mathrm{df}=24, \mathrm{p}$-value $=0.826)$, Stimulation $(\mathrm{t}=1.0589, \mathrm{df}=24, \mathrm{p}$-value $=0.3002)$, Hedonism $(\mathrm{t}=-0.2394$, $\mathrm{df}=24, \mathrm{p}$-value $=0.8128)$, Tradition $(\mathrm{t}=-0.4299, \mathrm{df}=24, \mathrm{p}$-value $=0.6711)$, Power $(\mathrm{t}=-0.543, \mathrm{df}=$ 24 , $p$-value $=0.5921)$. Hypothesis $H^{1.1 a}$ is thus not supported.

With the exception of the Stimulation scale, one-way ANOVAs indicated that there were no significant differences in the average value-orientation scale scores, on any other of the scales, between the various age groups: Benevolence $(\mathrm{df}=4,21, \mathrm{~F}=1.8919$, $\mathrm{p}$-value $=0.1494)$, Conformity $(\mathrm{df}=4,21, \mathrm{~F}$ $=0.6409, \mathrm{p}$-value $=0.6392)$, Achievement $(\mathrm{df}=4,21, \mathrm{~F}=0.2552, \mathrm{p}$-value $=0.9032)$, Universalism (df $=4,21, \mathrm{~F}=0.1682, \mathrm{p}$-value $=0.9522)$, Self Direction $(\mathrm{df}=4,21, \mathrm{~F}=1.0822, \mathrm{p}$-value $=0.3905)$, Security $(\mathrm{df}=4,21, \mathrm{~F}=1.1218, \mathrm{p}$-value $=0.3729)$, Hedonism $(\mathrm{df}=4,21, \mathrm{~F}=2.3816, \mathrm{p}$-value $=$ $0.0842)$, Tradition $(\mathrm{df}=4,21, \mathrm{~F}=0.3007, \mathrm{p}$-value $=0.8742)$, Power $(\mathrm{df}=4,21, \mathrm{~F}=0.3103, \mathrm{p}$-value $=$ $0.8678)$. Significant differences in the average Stimulation scores existed between the age groups $(F=$ $3.4448, \mathrm{df}=4,21, \mathrm{p}$-value $=0.0258$ ). Tukey's HSD test revealed that there were significant differences between the average 30-39 and 50-59 Stimulation scales scores ( $p$-value $=0.0379)$. The 
30-39 year old respondents had significantly lower scores than the 50-59 respondents, indicating that the 30-39 respondents felt that life was less exciting, novel and varied than their counterparts aged 5059. Hypothesis $\mathrm{H}^{1.1 \mathrm{~b}}$ is thus not supported except for the relationship between Stimulation and age.

One-way ANOVAs indicated that there were no significant differences in the average value-orientation scale scores between the various cultural groups: Benevolence $(\mathrm{df}=2,22, \mathrm{~F}=1.1516, \mathrm{p}$-value $=$ $0.3345)$, Conformity $(\mathrm{df}=2,22, \mathrm{~F}=0.84, \mathrm{p}$-value $=0.4451)$, Achievement $(\mathrm{df}=2,22, \mathrm{~F}=2.0534, \mathrm{p}$ value $=0.1522)$, Universalism $(\mathrm{df}=2,22, \mathrm{~F}=1.9431, \mathrm{p}$-value $=0.1671)$, Self Direction $(\mathrm{df}=2,22, \mathrm{~F}=$ 2.4611, $p$-value $=0.1085)$, Security $(d f=2,22, F=0.8841, p$-value $=0.4273)$, Stimulation $(d f=2,22$, $\mathrm{F}=3.1402, \mathrm{p}$-value $=0.0631)$, Hedonism $(\mathrm{df}=2,22, \mathrm{~F}=1.0132, \mathrm{p}$-value $=0.3794)$, Tradition $(\mathrm{df}=2$, $22, \mathrm{~F}=0.3213, \mathrm{p}$-value $=0.7286)$, Power $(\mathrm{df}=2,22, \mathrm{~F}=0.7707, \mathrm{p}$-value $=0.4748)$. There were only three levels of this factor, namely Black, Indian and White, as the Coloured respondents were the cases 'cleaned' or removed from this data set as described previously. Hypothesis $\mathrm{H}^{1.1 c}$ is thus not supported.

\section{Life-orientation of managers}

These data were cleaned using similar criteria to those of Schwartz (2009), namely dropping subjects who leave 7 (approximately 25\%) or more items blank or who leave $30 \%$ of the items for a scale blank. This resulted in the removal of two respondents. As can be seen in Table 3, Manageability and Comprehensibility were more important to managers than Meaningfulness. These data provided insufficient evidence that the life-orientation (SOC) scales have unequal population variances (Bartlett's K-squared $=0.663, \mathrm{df}=2, p$-value $=0.7179$ ). A one-way ANOVA indicated that there were significant differences in the average scores for Manageability, Comprehensibility and Meaningfulness $(F=8.3585, \mathrm{df}=2,69, \mathrm{p}$-value $=0.0006)$. Tukey's honest significant differences (HSD) post-hoc comparison test indicated that there were significant differences in the average scores for Comprehensibility and Meaningfulness $(p-v a l u e=0.0050)$ and Manageability and Meaningfulness $(p-$ value $=0.0010$ ). Manageability and Comprehensibility were therefore more important to managers than Meaningfulness as shown in Table 3.

Table 3: Life-orientation (SOC)- Antonovsky (1997) Questionnaire

\begin{tabular}{|l|l|l|l|}
\hline $\begin{array}{l}\text { Life-orientation } \\
\text { (SOC scales) }\end{array}$ & Valid N & Mean & Standard Deviation \\
\hline Manageability & 28 & 53.3214 & 6.5039 \\
\hline Comprehensibility & 28 & 52.8214 & 7.0082 \\
\hline Meaningfulness & 28 & 46.0357 & 5.8594 \\
\hline
\end{tabular}

Separate Levene's tests indicated that these data provided sufficient evidence that the male and female populations had significantly different population variances. Separate t-tests were conducted on each life-orientation scale, using separate estimates for the population variances. No significant differences were found between the average Comprehensibility and Manageability orientation scales and gender, at the $5 \%$ level of significance: Comprehensibility $(t=-0.8989, \mathrm{df}=11.359, \mathrm{p}$-value $=$ $0.3874)$, Manageability $(t=1.0359, \mathrm{df}=12.96, \mathrm{p}$-value $=0.3192)$. There was a significant difference between the average Meaningfulness orientation scale and gender, at the $5 \%$ level of significance: Meaningfulness $(t=2.2344, d f=13.713, p$-value $=0.0426) . H^{1.2 a}$ is thus not supported except in terms of Meaningfulness and gender.

One-way ANOVAs indicated that there were no significant differences between the average scores, on any of the life-orientation scales and the various age groups at the $5 \%$ level of significance: Comprehensibility $(F=0.693, d f=4,23, p$-value $=0.6044)$, Manageability $(F=1.5522, d f=4,22, p$ value $=0.2206)$, Meaningfulness $(F=0.9406, d f=4,24, p$-value $=0.4582) . \quad H^{1.2 b}$ is thus not supported.

One-way ANOVAs indicated that there were no significant differences in the average scores, on the Comprehensibility and Manageability scales between the various cultural groups at the $5 \%$ level of significance: Comprehensibility $(\mathrm{df}=3,23, \mathrm{~F}=1.9342, \mathrm{p}$-value $=0.1522)$, Manageability $(\mathrm{df}=3,23, \mathrm{~F}$ $=0.7482, \mathrm{p}$-value $=0.5345)$. However, significant differences in the average Meaningfulness scores existed between the various cultural groups $(F=3.7037, \mathrm{df}=3,23, \mathrm{p}$-value $=0.02612)$. Tukey's HSD test revealed that there were significant differences between the average African and Indian 
Meaningfulness scales scores ( $p$-value $=0.0263$ ) and the average White and Indian Meaningfulness scale scores $(p$-value $=0.0416)$. The Indian respondents had significantly higher average scores than the African and White respondents At the $5 \%$ level of significance, hypothesis $\mathrm{H}^{1.2 \mathrm{c}}$ is thus not supported, except for the difference in average score of Meaningfulness and cultural groups.

\section{Job satisfaction of managers}

These data were cleaned using similar criteria to those of Schwartz (2009), namely dropping subjects who left 15 (approximately 25\%) or more items blank or who left 30 per cent of the items for a scale blank. This resulted in the removal of six respondents. The Supervision, Co-workers, and Work scales have 18 items each, whereas the Pay and Promotion scales have 9 items each. As a result the scores on the Pay and Promotion scales were doubled to equate the possible ranges on the five scales. The scores were then summed to obtain five scale scores, resulting in each scale having a potential range of 0 to 54 (Kantor, 1991).

The results were compared using a scoring system of a general level of satisfaction developed and used by Pennington and Riley (1991: 24). Given that the maximum score for each job satisfaction scale, according to the JDI, is 54, the basic level of job satisfaction is indicated by the mid-point of 27. A highly dissatisfied response is indicated by a score of 13.5 or below, while a moderately dissatisfied response is indicated by a score above 13.6, but at or below the mid-point of 27 . Scores between 27 and 40.5 are evaluated as moderately satisfied responses, while those above 40.5 are assessed as highly satisfied, as shown in Table 4.

Table 4: Job satisfaction - Smith et al. (1969) Job Descriptive Index (JDI)

\begin{tabular}{|l|l|l|l|}
\hline $\begin{array}{l}\text { Job } \\
\text { Satisfaction } \\
\text { (JDI scales) }\end{array}$ & Mean & Standard Deviation & Pennington and Riley (1991) Rating \\
\hline Co-Workers & 41.7826 & 9.3951 & Highly satisfied \\
\hline Supervisors & 40.2727 & 13.5933 & Moderately satisfied \\
\hline Work & 38.8695 & 7.9561 & Moderately satisfied \\
\hline Pay & 26.7500 & 15.2294 & Moderately dissatisfied \\
\hline Promotion & 19.1666 & 15.7139 & Moderately dissatisfied \\
\hline
\end{tabular}

As shown in Table 4 there was generally a highly satisfied response to Co-workers and moderately satisfied with Work and Supervisors. As the mean scores were very close to 40.5 it can be seen that the parastatal had a positive work environment and employees were generally satisfied with supervisors. However there were two main areas with which respondents were dissatisfied, namely, Pay and Promotion. The relevant closeness of the pay and promotion mean scores indicated that respondents viewed these two scales of job satisfaction as being relatively similar. There was also a general feeling that the selected parastatal was an organisation in which it was difficult to be promoted, as indicated by the mean score for Promotions of 19.16 . Fourteen (47\%) of the respondents indicated that there were limited promotional opportunities.

The mean and standard deviation of the job satisfaction (JDI) scale scores are shown Table 4 (above). These data provided sufficient evidence that the job satisfaction scales had unequal population variances (Bartlett's K-squared $=14.5708, \mathrm{df}=4, \mathrm{p}$-value $=0.0057$ ). These scales did not have equal medians (Kruskal-Wallis chi-squared $=34.5403, \mathrm{df}=4, \mathrm{p}$-value $=5.773 \mathrm{e}-07$ ). Pairwise Wilcoxon Rank Sum Tests, using Holm's method to adjust the $p$-value for the multiple comparisons, showed significant differences in the average scores between Co-Workers and Pay ( $p$-value $=0.0069)$; CoWorkers and Promotion ( $p$-value $=0.0001)$; Pay and Supervision ( $p$-value $=0.0171)$; Pay and Work $(p$-value $=0.0171) ;$ Promotion and Supervision $(p$-value $=0.0007) ;$ Promotion and Work $(p$-value $=$ 0.0006).

Levene's tests indicated that these data provided sufficient evidence that the male and female populations had significantly different population variances. Separate t-tests were conducted on each job satisfaction scale, using separate estimates for the population variances. No significant differences were found between the average scale scores for each gender, at the $5 \%$ level of significance: CoWorkers $(\mathrm{t}=-0.8514, \mathrm{df}=6.971, \mathrm{p}$-value $=0.4228)$, Supervisors $(\mathrm{t}=-1.5186, \mathrm{df}=6.175, \mathrm{p}$-value $=$ $0.1783)$, Work $(\mathrm{t}=-1.1624, \mathrm{df}=18.569, \mathrm{p}$-value $=0.2598)$, Pay $(\mathrm{t}=1.7438, \mathrm{df}=8.76, \mathrm{p}$-value $=$ 
0.1161), Promotion $(t=-0.8908, d f=10.444, p$-value $=0.3931)$. Hypothesis $H^{1.3 a}$ is thus not supported.

One-way ANOVAs indicated that there were no significant differences in the average job satisfaction scale scores, on any other of the scales, between the various age groups at the $5 \%$ level of significance: Co-Workers $(\mathrm{df}=4,18, \mathrm{~F}=0.2833, \mathrm{p}$-value $=0.8850)$, Supervisors $(\mathrm{df}=4,17, \mathrm{~F}=$ 1.762, $p$-value $=0.1831)$, Work $(d f=4,18, F=0.771, p$-value $=0.5581)$, Pay $(d f=4,19, F=0.2693$, $p$-value $=0.8940)$, Promotion ( $d f=4,19, F=0.6981, p$-value $=0.6027)$. Hypothesis $\mathrm{H}^{1.3 b}$ is thus not supported.

With the exception of the Pay scale, one-way ANOVAs indicated that there were no significant differences in the average JS scale scores between the various cultural groups, at the $5 \%$ level of significance: Co-Workers $(\mathrm{df}=2,20, \mathrm{~F}=0.7057, \mathrm{p}$-value $=0.5056)$, Supervisors $(\mathrm{df}=2,19, \mathrm{~F}=$ $0.2061, p$-value $=0.8156)$, Work $(\mathrm{df}=2,20, F=1.6152, p$-value $=0.2237)$, Promotion $(\mathrm{df}=2,21, \mathrm{~F}=$ $2.2645, \mathrm{p}$-value $=0.1287$ ). Significant differences in the average pay scores existed between the cultural groups $(\mathrm{df}=2,21, \mathrm{~F}=4.3604, \mathrm{p}$-value $=0.02607$ ). Tukey's HSD test revealed that there were significant differences between the average 'white' and 'black' pay scales scores ( $p$-value $=0.0439$ ). The 'white' respondents had significantly higher pay scores than the 'black' respondents, indicating that the 'white' respondents value pay more. Note that there are only three levels of this factor, namely Black, Indian and White, as the Coloured respondents were the cases 'cleaned' or removed from this data set as described previously. Hypothesis $\mathrm{H}^{1.3 \mathrm{c}}$ is thus not supported, except between pay scales and the White and Black respondents, at the $5 \%$ level of significance.

\section{Relationship between value- and life-orientation and job satisfaction}

Pearson's correlation coefficient was used to assess the linear relationship between the various scales of the value-orientation, life-orientation and job satisfaction scales. Pair-wise complete observations were used in the calculation of Pearson's correlation coefficient.

As shown in Table 5, significant negative linear relationships were found between the following Valueorientation scales: Conformity and Stimulation $(r=-0.582, p$-value $=0.0028)$, Tradition and Stimulation $(r=-0.4321, p$-value $=0.0350)$, Benevolence and Self Direction $(r=-0.5540, p$-value $=0.0050)$, Benevolence and Stimulation $(r=-0.4095, p$-value $=0.0469)$, Universalism and Power $(r=-0.4154, p$ value $=0.0435$ ), and Achievement and Security $(r=-0.4931, p$-value $=0.0143)$. Significant positive linear relationships were found between Conformity and Benevolence $(r=0.5249, p$-value $=0.0084$, and Achievement and Power $(r=0.4872, p$-value $=0.0158)$. Hypothesis $\mathrm{H}^{2.1}$, that there are statistically significant linear relationships between the scales of the value-orientation instrument, is thus supported at the $5 \%$ significance level with regard to the above-mentioned significant linear relationships.

For the sake of brevity, the following abbreviations were used to represent the value-orientation scales in the following relevant tables, namely Conformity (CON), Tradition (TRA), Benevolence (BEN), Universalism (UNI), Self Direction (SELFD), Stimulation (STIM), Hedonism (HED), Achievement $(\mathrm{ACH})$, Power, (POW), and Security (SEC). 
Table 5: Pearson correlation coefficients (lower triangular elements) and associated p-values (upper triangular elements) for the scales of the value-orientation (SVS) instrument

\begin{tabular}{|c|l|l|l|l|l|l|l|l|l|l|}
\hline $\begin{array}{l}\text { Value- } \\
\text { orienta-tion } \\
\begin{array}{l}\text { Scales } \\
\text { (SVS) }\end{array}\end{array}$ & CON & TRA & BEN & UNI & SELFD & STIM & HED & ACH & POW & SEC \\
\hline CON & 1 & 0.8919 & 0.0084 & 0.8427 & 0.2081 & 0.0028 & 0.6269 & 0.3482 & 0.8681 & 0.9156 \\
\hline TRA & -0.0293 & 1 & 0.6700 & 0.8144 & 0.8521 & 0.0350 & 0.3138 & 0.5053 & 0.2511 & 0.4806 \\
\hline BEN & 0.5249 & 0.0917 & 1 & 0.2572 & 0.0050 & 0.0469 & 0.3925 & 0.1364 & 0.2622 & 0.3231 \\
\hline UNI & 0.0428 & -0.0506 & 0.2407 & 1 & 0.0882 & 0.5483 & 0.1339 & 0.1656 & 0.0435 & 0.1806 \\
\hline SELFD & -0.2665 & -0.0402 & -0.5540 & -0.3555 & 1 & 0.0531 & 0.3563 & 0.3824 & 0.5099 & 0.1450 \\
\hline STIM & -0.5820 & -0.4321 & -0.4095 & -0.1289 & 0.3994 & 1 & 0.1923 & 0.9088 & 0.1761 & 0.9678 \\
\hline HED & -0.1045 & -0.2147 & -0.1828 & -0.3150 & -0.1970 & 0.2757 & 1 & 0.3717 & 0.1963 & 0.0978 \\
\hline ACH & -0.2002 & -0.1429 & -0.3130 & -0.2924 & 0.1867 & -0.0247 & 0.1908 & 1 & 0.0158 & 0.0143 \\
\hline POW & 0.0358 & -0.2437 & -0.2383 & -0.4154 & -0.1414 & -0.2856 & 0.2733 & 0.4872 & 1 & 0.9608 \\
\hline SEC & -0.0229 & -0.1512 & 0.2107 & 0.2828 & -0.3067 & -0.0087 & -0.3459 & -0.4931 & 0.0106 & 1 \\
\hline
\end{tabular}

Significant positive linear relationships were found between the following life-orientation (SOC) scales: Manageability and Meaningfulness $(r=0.6210, p$-value $=0.0012)$, Comprehensibility and Meaningfulness $(r=0.4229$, $p$-value $=0.0395)$. No significant positive linear relationship existed between Comprehensibility and Manageability $(r=0.3866, p$-value $=0.0621)$. Hypothesis $H^{2.2}$, that there are statistically significant linear relationships between the scales of the life-orientation instrument, is thus supported at the $5 \%$ significance level with regard to the above-mentioned significant linear relationships.

With regard to job satisfaction, no significant linear relationships, as shown in Table 6, were found between the scales on the JDI instrument. Hypothesis $\mathrm{H}^{2.3}$, that there are statistically significant linear relationships between the scales of the job satisfaction instrument, is thus not supported at the $5 \%$ significance level.

Table 6: Pearson correlation coefficients (lower triangular elements) and p-values (upper triangular elements) for the scales of the job satisfaction (JDI) instrument

\begin{tabular}{|l|l|l|l|l|l|}
\hline $\begin{array}{l}\text { Job } \\
\text { Satisfaction } \\
\text { (JDI scales) }\end{array}$ & Work & Supervision & Co Workers & Pay & Promotion \\
Work & 1 & 0.8652 & 0.1068 & 0.9899 & 0.4473 \\
\hline Supervision & 0.0366 & 1 & 0.8937 & 0.3283 & 0.8885 \\
\hline Co Workers & 0.3374 & 0.0288 & 1 & 0.4283 & 0.7833 \\
\hline Pay & 0.0027 & -0.2085 & 0.1696 & 1 & 0.2587 \\
\hline Promotion & 0.1628 & 0.0302 & -0.0592 & -0.2400 & 1 \\
\hline
\end{tabular}

Significant negative linear relationships, shown in Table 7, were found between the following scales on the value-orientation (SVS) and life-orientations (SOC) instruments: Benevolence and Manageability ( $r$ $=-0.4048, p$-value $=0.0497)$, Benevolence and Meaningfulness $(r=-0.5219, p$-value $=0.0089)$. Significant positive linear relationships, shown in Table 7, were found between the following scales on the value-orientation (SVS) and life-orientations (SOC) instruments: Self-direction and Meaningfulness $(r=0.5187, p$-value $=0.0094)$, Stimulation and Meaningfulness $(r=0.4343, p$-value $=0.0340)$. Hypothesis $H^{3.1}$, that there are statistically significant linear relationships between the scales of the 
value- and life-orientation instruments, is thus supported at the $5 \%$ significance level with regard to the negative linear relationships between Benevolence and Manageability; Benevolence and Meaningfulness and the positive relationships between Self-Direction and Meaningfulness; and Stimulation and Meaningfulness.

Table 7: Pearson correlation coefficients and associated p-values for the scales of the value-orientation (SVS) and life-orientation (SOC) instrument (p-values are shown in brackets)

\begin{tabular}{|l|l|l|l|l|l|l|l|l|l|l|}
\hline $\begin{array}{l}\text { SVS ISOC } \\
\text { Scales }\end{array}$ & CON & TRA & BEN & UNI & SELFD & STIM & HED & ACH & POW & SEC \\
\hline $\begin{array}{l}\text { Compre- } \\
\text { hensibility }\end{array}$ & $\begin{array}{l}0.2493 \\
(0.2401)\end{array}$ & -0.1995 & -0.1207 & 0.2188 & -0.0620 & 0.0470 & 0.3794 & -0.0112 & -0.1379 & -0.2336 \\
\hline $\begin{array}{l}\text { Manage- } \\
\text { ability }\end{array}$ & -0.1573 & -0.1760 & -0.4048 & -0.2482 & 0.4021 & 0.1131 & 0.2619 & 0.1525 & -0.0148 & -0.3280 \\
\hline $\begin{array}{l}\text { Meaning- } \\
\text { fulness }\end{array}$ & $(0.4628)$ & $(0.4107)$ & $(0.0497)$ & $(0.2422)$ & $(0.0514)$ & $(0.5987)$ & $(0.2163)$ & $(0.4767)$ & $(0.9453)$ & $(0.1176)$ \\
\hline
\end{tabular}

Significant negative linear relationships, shown in Table 8, were found between the following scales on the value-orientation (SVS) and job satisfaction (JDI) instruments: Stimulation and Supervision $(r=-$ 0.4884 , $p$-value $=0.0155)$, Achievement and Pay $(r=-0.4131$, $p$-value $=0.0448)$, Power and Pay $(r=-$ $0.6515, p$-value $=0.0006$ ). Hypothesis $\mathrm{H}^{3.2}$, that there are statistically significant linear relationships between the scales of the value-orientation and job satisfaction instruments, is thus supported at the $5 \%$ significance level in terms of the above-mentioned relationships.

Table 8: Pearson correlation coefficients and associated levels of significance for the scales of the value-orientation (SVS) and job satisfaction (JDI) instruments (p-values are shown in brackets)

\begin{tabular}{|c|c|c|c|c|c|c|c|c|c|c|}
\hline $\begin{array}{l}\text { SVS/JDI } \\
\text { Scales }\end{array}$ & CON & TRA & BEN & UNI & SELFD & STIM & HED & $\mathrm{ACH}$ & POW & SEC \\
\hline Work & (0.6187) & \begin{tabular}{|l}
0.1231 \\
$(0.5665)$
\end{tabular} & $\begin{array}{l}0.1132 \\
(0.5986)\end{array}$ & \begin{tabular}{|l}
-0.1770 \\
$(0.4081)$
\end{tabular} & \begin{tabular}{|l|}
0.2808 \\
$(0.1838)$
\end{tabular} & \begin{tabular}{|l|}
-0.2524 \\
$(0.2340)$
\end{tabular} & & \begin{tabular}{|l|}
0.0507 \\
$(0.8138)$
\end{tabular} & $\begin{array}{l}0.1387 \\
(0.5179)\end{array}$ & \begin{tabular}{|l|}
0.0582 \\
$(0.7872)$
\end{tabular} \\
\hline $\begin{array}{l}\text { Supervi- } \\
\text { sion }\end{array}$ & $\begin{array}{l}0.3931 \\
(0.0574)\end{array}$ & \begin{tabular}{|l|}
0.2764 \\
$(0.1910)$
\end{tabular} & & & $\begin{array}{l}-0.2523 \\
(0.2343)\end{array}$ & & & \begin{tabular}{|l|}
0.1941 \\
$(0.3635)$
\end{tabular} & & \begin{tabular}{|c|}
-0.3492 \\
$(0.0944)$
\end{tabular} \\
\hline $\begin{array}{l}\text { Co- } \\
\text { Workers } \\
\end{array}$ & $\begin{array}{l}0.0199 \\
(0.9264)\end{array}$ & \begin{tabular}{|l|l|}
0.1446 \\
$(0.5002)$ \\
\end{tabular} & $\begin{array}{l}0.0022 \\
(0.9917) \\
\end{array}$ & \begin{tabular}{|l|l|}
0.1269 \\
$(0.5547)$ \\
\end{tabular} & \begin{tabular}{|l|l|}
0.1704 \\
$(0.4259)$ \\
\end{tabular} & & \begin{tabular}{|l}
-0.1705 \\
$(0.4258)$
\end{tabular} & \begin{tabular}{|l}
-0.1104 \\
$(0.6076)$ \\
\end{tabular} & & \begin{tabular}{|l|l|}
0.2413 \\
$(0.2560)$ \\
\end{tabular} \\
\hline Pay & $\begin{array}{l}-0.1945 \\
(0.3623)\end{array}$ & \begin{tabular}{|l|}
0.0697 \\
$(0.7462)$
\end{tabular} & $\begin{array}{l}0.1392 \\
(0.5165)\end{array}$ & \begin{tabular}{|l|}
0.2092 \\
$(0.3264)$
\end{tabular} & \begin{tabular}{|l|}
0.0534 \\
$(0.8042)$
\end{tabular} & \begin{tabular}{|l|}
0.2618 \\
$(0.2166)$
\end{tabular} & \begin{tabular}{|l|}
-0.0875 \\
$(0.6844)$
\end{tabular} & \begin{tabular}{|l|}
-0.4131 \\
$(0.0448)$
\end{tabular} & $\begin{array}{l}-0.6515 \\
0.0006\end{array}$ & \begin{tabular}{|l|}
0.1387 \\
$(0.5180)$
\end{tabular} \\
\hline $\begin{array}{l}\text { Promo- } \\
\text { tion }\end{array}$ & $\begin{array}{l}0.1464 \\
(0.4950)\end{array}$ & $\begin{array}{l}-0.1773 \\
(0.4071)\end{array}$ & $\begin{array}{l}0.1016 \\
(0.6365)\end{array}$ & $\begin{array}{l}0.0487 \\
(0.8211)\end{array}$ & $\begin{array}{l}-0.1396 \\
(0.5154)\end{array}$ & $\begin{array}{l}-0.1383 \\
(0.5192)\end{array}$ & $\mid \begin{array}{l}0.1044 \\
(0.6272)\end{array}$ & $\begin{array}{l}-0.0066 \\
(0.9758)\end{array}$ & $\begin{array}{l}0.2323 \\
(0.2748)\end{array}$ & $\begin{array}{l}0.1722 \\
(0.4210)\end{array}$ \\
\hline
\end{tabular}

Significant positive linear relationship, as illustrated in Table 9, was found between the following lifeorientation (SOC) and job satisfaction (JDI) instrument scales: Comprehensibility and Promotion $(r=$ 0.532 , $p$-value $=0.0075$ ). Hypothesis $\mathrm{H}^{3.3}$, that there are statistically significant linear relationships between the scales of the life-orientation and job satisfaction instruments, is thus not supported at the $5 \%$ significance level except for the above-mentioned relationship. 
Table 9: Pearson correlation coefficients and associated level of significance for the scales of the life-orientation (SOC) and job satisfaction (JDI) instruments ( $p$-values are shown in brackets)

\begin{tabular}{|l|l|l|l|}
\hline $\begin{array}{l}\text { SOC/JDI } \\
\text { Scales }\end{array}$ & Comprehensibility & Manageability & Meaningfulness \\
\hline Work & -0.1983 & -0.0430 & 0.1081 \\
& $(0.3529)$ & $(0.8419)$ & $(0.6150)$ \\
\hline Supervision & 0.2610 & 0.1907 & -0.1048 \\
& $(0.2179)$ & $(0.3721)$ & $(0.6260)$ \\
\hline Co-Workers & 0.1547 & 0.1480 & 0.1974 \\
& $(0.4705)$ & $(0.4901)$ & $(0.3551)$ \\
\hline \multirow{2}{*}{ Pay } & -0.0890 & 0.0151 & 0.0805 \\
& $(0.6791)$ & $(0.9440)$ & $(0.7085)$ \\
\hline Promotion & 0.5320 & 0.2326 & 0.0443 \\
& $(0.0075)$ & $(0.2741)$ & $(0.8370)$ \\
\hline
\end{tabular}

\section{DISCUSSION OF FINDINGS}

\section{Value orientation of managers}

Focusing on Schwartz value survey, social values such as Benevolence and Conformity were most important. This could be attributed to the organisational culture in a parastatal organisation. Values of Benevolence include being helpful, caring, honest, enhancing the welfare of people while Conformity includes politeness, obedience and honouring elders. This finding is contrary to previous research in an international automotive context in South Africa in which Universalism was the dominant value (Mayer, 2011), indicating that in an international setting, being broad- minded is more important.

Significant differences were found with regard to the value of Stimulation and age. The 30-39-year-old respondents had significantly lower scores than the 50-59 respondents, indicating that the 30-39 respondents felt that life was less exciting, novel and varied than their counterparts aged 50-59. This finding is contrary to the previous research by Schwartz (2005) indicating that Stimulation values should decrease with age. No significant differences in the average value-orientation scale scores were found with regard to gender and cultural groups. The results of this research are similar to Schwartz (2006) who asserted that gender differences in values were small.

\section{Life-orientation of managers}

There were significant differences in the average scores for life-orientation (SOC) particularly between Manageability and Meaningfulness and between Comprehensibility and Meaningfulness, indicating that Meaningfulness was less important in both instances. This result indicates that it is important for managers to understand a situation and to deal with it appropriately without interpreting the deeper meaning of the situation and contextualising challenging work to their personal purpose in life. These findings are confirmed by previous research in the South African Automotive industry (Mayer, 2011). With regard to life-orientation and gender, previous research has found that males score higher than females (Lindström \& Eriksson 2005: 462; Mayer 2011: 336). In this research a significant difference was found in the average Meaningfulness score between males and females, indicating that female managers scored higher in Meaningfulness. It is evident in from this research that female managers relate situations and experiences at work more to the meaning of their personal life and their purpose in life than male managers do. Bengal et al. (2001) confirmed that a sense of Meaningfulness is considered the most important component in a person's life; without it, life is experienced as a burden. No significant differences were found between the mean values of the life-orientation scales and age.

No significant differences, between cultural groups, in the average scores on the Comprehensibility and Manageability were found. Significant differences between the average African and Indian Meaningfulness scale scores and the White and Indian Meaningfulness scale scores were found. The Indian respondents had significantly higher scores than the African and White respondents, indicating that the Indian respondents felt that they had more influence over the shaping of situations. 


\section{Job satisfaction of managers}

There was generally a highly satisfied response to co-workers, thus indicating that employees at the selected parastatal had a good working environment and were satisfied with their fellow workers. Similarly respondents indicated that they were moderately satisfied with work and Supervisor, indicating that the parastatal had a positive work environment and employees were generally satisfied with supervisors. Other research findings were mixed with regard to supervision, Lester (1985) found high satisfaction with supervision amongst teachers while Chen (cited in Pennington and Riley 1991:21) found the opposite. Respondents were dissatisfied with Pay and Promotion. The relevant closeness of the Pay and Promotion mean scores indicates that respondents viewed these two scales of job satisfaction as being relatively similar. It can also be noted that in other studies done with a similar or slightly greater sample size by Pennington and Riley $(1991: 24,27)$ the results and rank are very similar to those at the selected parastatal. There was also a general feeling that the selected parastatal was an organisation in which it was difficult to be promoted.

No significant differences were found between the average job satisfaction scale scores for gender and the various age groups. This is contrary to previous research as reported by Johnson and Johnson, (2010:541-542) where a positive association was found between age and job satisfaction as well as gender and job satisfaction. With regard to cultural groups, differences were found in the average pay for 'white' and 'black' respondents. The 'white' respondents had significantly higher pay scores than the 'black' respondents, indicating that the 'white' respondents valued pay more than the 'black' respondents did.

\section{The relationship between value- and life-orientation and job satisfaction of managers}

Significant negative linear relationships were found between the following value-orientation (SVS) scales: Conformity and Stimulation; Tradition and Stimulation; Benevolence and Self-direction; Benevolence and Stimulation; Universalism and Power; and Achievement and Security. A negative linear relationship implies that there are inverse relationships between these mentioned valueorientations. For example a high score (strong value) for Conformity would imply a lower score (weak value) for Stimulation and vice versa. If significant positive linear relationships were found between Conformity and Benevolence, and Achievement and Power, i.e. a strong value in Conformity would imply a strong value in Benevolence and vice versa. In this research, the Tradition scale had a low, 0.3653, Cronbach Alpha score. The linear relationship between Tradition and Stimulation should be interpreted with caution.

With regard to life-orientation scales, significant positive linear relationships were found between Manageability and Meaningfulness (managing situations and tasks reconstructs meaningfulness/purpose in life); and Comprehensibility and Meaningfulness (the more a manager understands the world, the more his purpose in life is enhanced). In terms of job satisfaction, no significant linear relationships were found between the scales on the JDI instrument.

Significant negative linear relationships were found between the following scales on the valueorientation (SVS) and life-orientation (SOC) instruments: Benevolence and Manageability, indicating that if there is too much concern about the well-being of others, successful managing of situations could become impaired; Benevolence and Meaningfulness, meaning that too much concern about others could also negatively impact on the individual's purpose in life. Further findings pointed to positive linear relationships between Self-direction and Meaningfulness, meaning that an increased sense of Self-direction would contribute positively towards creating Meaningfulness in life and vice versa; and Stimulation and Meaningfulness, indicating that an increase in novelty and challenges in life would contribute towards a greater sense of Meaningfulness in life and vice versa. Previous research by Sage and Antonovsky (2000) has indicated that a stable value system promotes the development of a strong life-orientation.

The findings in this research support previous research by Verplanken (2004) in which it was found that values influence job satisfaction. Significant negative linear relationships were found between the following scales on the value-orientation and job satisfaction instruments: Stimulation and Supervision, indicating that it is possible for a manager who values stimulation highly, to be frustrated by close supervision; Achievement and Power with Pay. The nature of this study provides support for these 
findings. It seems that managers realise some of their achievement and power goals through social recognition and social status, rather than through pay. The research finding pertaining to Stimulation and Supervision is supported by Kass et al., 2001: 322-323) who confirmed that there is a positive relationship between types of boredom and dissatisfaction with supervision. Lee (1986) who reported significant and negative relationships between job boredom and the Job Descriptive Index facets of work itself, pay, promotion opportunities, supervision, co-workers, as well as with overall satisfaction scores. The research findings by Tang (2007:388) indicated that income was negatively related to quality of life as a value for full-time, high income male employees with the following conditions: "(i) the love of money is negatively correlated with job satisfaction and (ii) job satisfaction is positive related to income and quality of life". Tang's (2007) finding supports the idea that managers in this organisation would value achievement and power more than pay. It has also been asserted that extrinsic rewards, such as pay, have a negative impact on meaningful life satisfaction for high-income earners (Nickerson, Schwartz, Diener \& Kahneman 2003).

The finding that a significant positive linear relationship was found between a Sense of Comprehensibility and Promotion supports previous research by Rothmann (2001), Strümpfer et al. (1998), indicating that life-orientation is positively related to job satisfaction. The finding in this research shows that having a good understanding of a work situation impacts positively on promotion. Promotion, in turn, leads to increased levels of Comprehensibility within the organisational setting. Although different research instruments were used to those in this study, previous research has confirmed that there are reciprocal relationships between subjective well-being and job satisfaction (e.g. Houghton and Jinkerson, 2007:45) and significant relationships between quality of life and job satisfaction (Tang 2007:388).

\section{CONCLUSIONS AND RECOMMENDATIONS}

Managers in this parastatal organisation highly value socially orientated values such as Benevolence and Conformity, indicating a strong in-group, mutual support and a concern for society which reflects the vision and the nature of organisation. The mature generation, 50 years old and more, in this organisation, were more stimulated by the managerial challenges and took pleasure in it because they comprehended the broader context and had the opportunity of being able to manage a situation.

Referring to life-orientation, encouraging a stronger sense of meaningfulness should positively influence organisational meaning and managerial satisfaction in the work place. In turn, an increase in job satisfaction should increase the Sense of Coherence (including mental health) in a manager's life. Managers were more satisfied in their job with the qualities of work itself, supervision and co-workers (intrinsic rewards) than with pay and promotional opportunities (extrinsic rewards). Since managers at the selected organisation scored highest in Benevolence, it could be assumed that this value would contribute towards the overall job satisfaction scores, specifically to moderate to high satisfaction with intrinsic rewards. It is interesting that 'white' respondents valued pay more than the 'black' respondents did.

Although female managers scored lower in life-orientation than males, they scored higher in Meaningfulness. This unique finding indicates that the female approach of creating meaning within the parastatal should be further explored by management. Belonging to cultural groups also impacted on life-orientation. In this regard, an important assumption can be made that members of minority groups require a higher sense of Meaningfulness to use their values in life to deal with the challenges in the South African work place.

Significant negative and positive linear relationships were found between certain value-orientated scales, as discussed in the previous section. With regard to life-orientation scales, significant positive linear relationships were found amongst Meaningfulness, Manageability and Comprehensibility. In terms of job satisfaction no significant linear relationships were found between the job satisfaction scales.

With reference to the value- and life-orientation, this exploratory research revealed that there were significant negative and positive linear relationships between certain scales as highlighted in the discussion section of this article. Negative linear relationships, as discussed in the previous section, were found between value-orientation and job satisfaction, while there was a positive linear 
relationship between the life-orientation value of Comprehensibility and the job satisfaction component of Promotion.

Based on the findings and conclusions in this research, the following recommendations are made:

- Values of Benevolence and Conformity should become tacit knowledge which could then become more consciously perceived by all employees, thereby contributing to organisational meaningfulness and a healthy sense of coherence.

- The relationship between Benevolence and job satisfaction should be further researched within a South African perspective.

- While the social values are imperative in establishing a meaningful organisational culture, it is recommended that values pertaining to Universalism should be strengthened, together with Meaningfulness, in organisations. Universalistic values should be embedded in the creation of meaningfulness, extending the embedded value beyond the social to the natural environment.

- The younger generation needs to be inspired by the mature generation, and shared experiences and knowledge need to be integrated across the age groups. In addition, appropriate stimuli need to be created for the younger generation. It would be beneficial for the organisation to devote greater attention to the systematic assessment of different perceptions and experiences of creativity and innovation across the age groups.

- Even though managers seemed to be dissatisfied with the pay and opportunity for promotion, the negative linear relationship between their values for Achievement and Power with Pay indicates that the selected organisation should build on these values. The relationship between achievement and power should be further researched.

- The ability of females to integrate work and life in which work is viewed as a part of their life and contributes to the purpose of life, a sense of Meaningfulness, needs to be further researched.

- The preliminary finding that minority groups have a higher Meaningfulness score requires further research and a discussion on the meaningfulness of an individual's contribution across cultures in the work place should be stimulated.

- With regard to job satisfaction, further research on the effect of Meaningfulness on Pay and Promotion should be undertaken as well as the value perceptions of pay by different cultural groups.

- The statistically significant relationships between value- and life-orientation and job satisfaction should be confirmed in other organisations and with larger sample sizes. In particular, the impact of cross-cultural aspects on organisations should be further researched.

\section{REFERENCES}

Alarcon GM. \& Lyons JB. 2011. The relationship of engagement and job-satisfaction in working samples. The Journal of Psychology: Interdisciplinary and applied, 145(5): 463-480.

Alessandri G Veccione M. Tisak J Deiana G Caria S Caprara GV. 2012. The utility of Positive Orientation in Predicting Job Performance and Organisational Citizenship Behaviours. Applied Psychology: An International Review (1):1-30.

Antonovsky A. 1979. Health, stress, and coping: new perspectives on mental and physical wellbeing. San Francisco: Jossey-Bass.

Antonovsky A. 1987. Unravelling the mystery of health: how people mange stress and stay well. San Francisco: Jossey-Bass.

Antonovsky A. 1993. The structure and properties of the sense of coherence scale. Social Science Medical Journal, 36(6): 725-733.

Antonovsky A. 1997. Salutogenese - Zur Entmystifizierung der Gesundheit. Tübingen: Dgtv-Verlag.

Arciniega LM \& Gonzalez L. 2003 Other-Oriented values and job satisfaction. Paper submitted to the 18th conference of the Society for Industrial Psychology, Orlando, FA April 2003, [Online] Available: http://administracion.itam.mx/workingpapers/Arciniega_y_Gonzalez_2003.pdf 
Arciniega LM \& González L. 2000.Desarrollo y validación de la escala de valores hacia el trabajo EVAT 30. Revista de Psicología Social, 15: 281-296.

Baloyi J. 2000. Confirmatory factor analysis on the measurement of six salutogenic constructs. Unpublished Masters Dissertation. Pretoria: University of South Africa.

Bengel J, Strittmatter R \& Willmann H. 2001. Was erhält Menschen gesund? Antonovskys Modell der Salutogenese - Diskussionsstand und Stellenwert. Forschung und Praxis der Gesundheitsförderung, Band 6. Köln: Bundeszentral für gesundheitliche Aufklärung.

Berkel K. 2005. Wertkonflikte als Drama - Reflexion statt Training. Wirtschaftspsychologie. Themenheft Konfliktprozesse in der betrieblichen Lebenswelt - Theorie, Konzepte, Pragmatik, $4(1): 2-8$.

Blättner B. 2007. Das Modell der Salutogenese: Eine Leitorientierung für die berufliche Praxis. Prävention und Gesundheitsförderung, 2: 67-72.

Burgess SM, Schwartz SH \& Roger D. 1995. Do values share universal content and structure? A South African Test. South African Journal of Psychology, 24(1): 1-12.

Burton JW. 1990. Conflict: Human Needs Theory. London: Macmillian.

Cilliers F \& Kossuth SP. 2004. The reliability and factor structure of three measures of salutogenic functioning. South African Journal of Labour Relations, 28 (2): 59-76.

Collis J \& Hussey R. 2003. Business Research: A practical guide for undergraduate and postgraduate students. ( $2^{\text {nd }}$ ed.). New York: Palgrave Macmillian.

Cranny CJ, Smith PC \& Stone EF. (Eds.). 1992. Job satisfaction: Advances in research and applications. New York: The Free Press.

Du Buisson-Narsai I. 2005. The Relationship Between Personal Meaning, Sense of Coherence and Organisational Commitment. Unpublished Master's Dissertation. Pretoria: University of South Africa.

Eliason BC, Guse C \& Gottlieb MS. 2000. Personal Values of Family Physicians, Practice Satisfaction, and Service to the Underserved. Archives of Family Medicine, 9: 228-232.

Fisher CD. 1998. Mood and emotions while working - missing pieces of job satisfaction. School of Business Discussion Papers. Paper 64. Queensland: Bond University. [Online] Available at: http://epublications.bond.edu.au/discussion_papers/64.

Fourie L, Rothmann S \& Van de Vijver AJR. 2008. A model of work wellness for non-professional counsellors in South Africa. Stress and Health, 24(1): 35-47.

Frenz AW, Carey MP \& Jorgensen RS. 1990. Measuring Antonovsky's sense of coherence construct: A psychometric study. Paper presented at the Convention of Eastern Psychological Association, Philadelphia, PA, March 1990.

Gandal N, Roccas S, Sagiv L \& Wrzesniewski A. 2005. Personal value priorities of economists. Human Relations, 58(10): 1227-1252.

Glen ND. 1974. Aging and conservatism. Annals of the American Academy of Political and Social Sciences, 415: 176-186.

Gruneberg, MM. 1979. Understanding Job-satisfaction. First Edition. London: Mc Millan Press.

Houghton JD \& Jinerson DL. 2007. Constructive thought strategies and job satisfaction: A preliminary examination. Journal of Business and Psychology, 22(1): 45-53. 
Howard F. 2008. Managing stress or enhancing wellbeing? Positive psychology's contributions to clinical supervision. Australian Psychologist, 43(2):105-113.

Jackson T. 2011. International Management Ethics. A Critical, Cross-cultural perspective. Cambridge: Cambridge University Press.

Jackson L \& Rothmann S. 2001. Sense of coherence, self efficacy, and locus of control as predictors of job satisfaction. Poster session presented at the $10^{\text {th }}$ European Congress on Work and Organisational Psychology, Praque, Czech Republic.16.-19 May.

Johnson GJ \& Johnson WR. 2010. Perceived overqualifications and dimensions of job-satisfaction; a longitudinal analysis. The Journal of Psychology: Interdisciplinary and Applied, 134(5): 537555.

Judge TA \& Hurst C. 2007. The benefits and possible costs of positive core self-evaluations: A review and agenda for further research. In Nelson D \& Cooper C (Eds.). Positive organizational behaviour. London: Sage (pp159-174).

Judge TA, Locke EA, Durham CC \& Kluger AN. 1998. Dispositional effects of job and life satisfaction: The role of core evaluations. Journal of Applied Psychology, 83(1): 17-34.

Kantor J. 1991. The effects of computer administration and identification on the Job Descriptive Index (JDI). Journal of Business and Psychology, 5(3): 309-323.

Kass SJ, Vodanovich SJ \& Callender A. 2001. State-trait boredom: Relationship to absenteeism, tenure and job satisfaction. Journal of Business and Psychology, 16(2): 317-327.

Kinicki AJ, McKeee-Ryan FM, Schriesheim CA \& Carson PK. 2002. Assessing the Construct Validity of the Job Descriptive Index: A review and Meta-analysis. Journal of Applied Psychology, 87 (1): 14-32.

Kivimaki M, Feldt T, Vahtera J \& Nurmi, JE. 2000. Sense of Coherence and health: Evidence from two cross-lagged longitudinal samples. Social Science and Medicine, 50: 583-597.

Kluckhohn FR \& Stroedbeck FL. 1961. Variations in value-orientations. Evanston: Row \& Peterson.

Lee TW. 1986. Toward the development and validation of a measure of job boredom. Manhattan College Journal of Business, 15: 22-28.

Lester PE. 1985. Teacher job satisfaction K-12. Illinois School Research and Development, 22(1): 3233.

Lindström B \& Eriksson M. 2005. Salutogenesis. Journal of Epidemiology and Community Health, 59(6): $440-442$.

Lindström B \& Eriksson M. 2006. Contextualizing salutogenesis and Antonovsky in public health development. Health Promotion International, 21(3): 238-244.

Lochner HD. 2000. The connection between psychological strengths and work satisfaction of employees in a manufacturing industry. Unpublished Masters Dissertation. Pretoria: University of South Africa.

Lustig DC \& Strauser DR. 2002. The relationship between sense of coherence and career thoughts. Career Development Quarterly, 51: 2-11.

Mayer C-H. 2008. Managing conflicts across cultures, values and identities. Marburg: Tectum Verlag. 
Mayer C-H. 2011. The meaning of Sense of Coherence in Transcultural Management. Internationale Hochschulschriften Series. Münster: Waxmann.

Mayer C-H \& Boness CM. 2009. Conflict, identity and sense of coherence in managers. A case study from South Africa. Journal of Contemporary Management, 6: 39-63 [Online] Available: http://www.sabinet.co.za/abstracts/jcman/jcman_v6_a3.html. (Accessed: 10 June 2009). , ISSN: 18157440

Mayer C-H \& Louw L. 2009. Organizational conflicts: Reflections on managing conflicts, identities and values in a selected South African organization. South African Journal of Human Resource Management, 7(1): 1-13.

Mayer C-H, Louw L \& Louw MJ. 2010. Sense of Coherence and organisational Commitment: A case study in a selected South African parastatal. Competitive Paper, $22^{\text {nd }}$ Annual Conference of the Southern Africa Institute for Management Scientists (SAIMS). Conference theme: A discourse on the influence of management. Does it matter? Mpekweni Beach Resort, Port Alfred, South Africa. 12-15 September 2010.

Muller Y \& Rothmann S. 2009. Sense of coherence and employees' perception of helping and restraining factors in an organization. South African Journal of Industrial Psychology, 35(1): 110.

Nickerson C, Schwarz N, Diener E and Kahneman D. 2003. Zeroing in on the Dark Side of the American Dream: A Closer Look at the Negative Consequences of the Goal for Financial Success. Psychological Science,14(6): 531-534.

Nunnally J. 1978. Psychometric theory. ( $2^{\text {nd }}$ ed.). New York: McGraw-Hill.

Pennington MC \& Riley PV. 1991. Measuring job satisfaction in ESL using the Job Descriptive Index. Perspectives, Working papers of the Department of English, City Polytechnic of Hong Kong, $3(1): 20-36$

Pillay K. 2008. Sense of coherence, work engagement and organisational commitment within an automotive development institute. Unpublished Master's Dissertation in Industrial and Organisational Psychology. Pretoria: University of South Africa. [Online] Available at: http://uir.unisa.ac.za/dspace/bitstream/10500/3168/1/dissertation_pillay_k.pdf. (Accessed: 03 May 2010).

R Development Core Team. 2010. R: A language and environment for statistical computing. $R$ Foundation for Statistical Computing. Vienna, Austria. [Online] Available at: http://www.Rproject.org/

Randall SJ. 2007. A validation study of the sense of coherence scale using two South African samples. Unpublished MA Dissertation. Johannesburg: University of Witwatersrand. [Online] Available from: http://wiredspace.wits.ac.za/handle/10539/2171?show=full (Accessed: 31 December 2010).

Rencher AC. 2005. Methods of Multivariate Analysis, Second Edition. New York: John Wiley \& Sons.

Robinson JP, Shaver PR \& Wrightsman LS. 1991. Criteria for scale selection and evaluation. In Robinson, JP, Shaver, PR and Wrightsman, LS. (Eds.). Measures of personality and social psychological attitudes. San Diego, CA: Academic Press. (pp. 1-16).

Ros M, Schwartz SH \& Surkiss S. 1999. Basic individual values, work values, and the meaning of work. Applied Psychology, 48(1): 49-71.

Rothmann S. 2001. Sense of coherence, locus of control, self-efficacy and job satisfaction. Journal of Economic and Management Sciences, 5: 41-65. 
Sagy S \& Antonovsky H. 2000. The development of the Sense of Coherence: A retrospective study of early life experiences in the family. The International Journal of Aging and Human Development Issue, 51(2):155-166.

Sarros JC \& Santora JC. 2001. Leaders and values: a cross-cultural study. Leadership and Organization Development Journal, 22(5): 243-248.

Schwartz SH. 1992. Universals in the content and structure of values: Theoretical advances and empirical tests in 20 countries. In Zanna, M.P. (Ed.). Advances in Experimental Social Psychology, 25(2): 1-65.

Schwartz SH. 1994. Are there universal aspects in the structure and content of human values? In Mayton, D.M., Loges, W. E., Ball-Rokeach, S.J. and Grube, J.W. (Eds). Human values and social issues: Current understanding and implications for the future. Journal of Social Issues, 50(4): 19-45.

Schwartz SH. 1999. A theory of cultural values and some implications for work applied Psychology. Applied Psychology: An International Review, 48(1): 23-47.

Schwartz SH. 2005. Robustness and fruitfulness of a theory of universals in individual human values. In: Tomayo, A. \& Porto, J.B. (Eds.). Valores e compartomento nas organizacoes. Petropolis, Brazil: Vozes. (pp. 21-55).

Schwartz SH. 2006. Les valeurs de base de la personne: Théorie, mesures et applications. Revue française de Sociologie, 42: 249-288.

Schwartz SH. 2009. Draft users manual: Proper use of the Schwarz Value Survey, version 14 January 2009. Compiled by Romie F. Littrell. Auckland, New Zealand: Centre for Cross Cultural Comparisons, [Online] Available: http://www.crossculturalcentre.homestead.com.

Schwartz SH \& Bardi A. 2001. Value hierarchies across cultures taking a similarities perspective. Journal of Cross-Cultural Psychology, 32(3):268-290.

Smith PC, Kendall LM \& Hulin CL. 1969. The measurement of satisfaction in work and retirement: A strategy for the study of attitudes. Chicago: Rand McNally.

Smith PC, Kendall LM \& Hulin CL. 1975. The measurement of satisfaction in work and retirement. Chicago: Rand McNally.

Smith PB, Peterson MF \& Schwartz SH. 2002. Cultural values, sources of guidance, and their relevance to managerial behaviour. A 47-nation study. Journal of Cross-Cultural Psychology, 33(2): 188-208.

Spini D. 2003. Measurement equivalence of 10 value types from the Schwartz Value Survey across 21 countries. Journal of Cross-Cultural Psychology, 34(1): 3-23.

Stewart EC, Danielian J \& Foster R. 1998. Cultural assumptions and values. In M.J. Bennett (Ed.). Basic concepts of intercultural communication. Selected readings. Maine: Intercultural.

Strümpfer DJW. 1990. Salutogenesis: A new paradigm. South African Journal of Psychology, 20: 4552.

Strümpfer DJW \& de Bruin GP. 2009. Antonovsky's Sense of Coherence and Job Satisfaction: Meta-Analyses of South African Data. SA Journal of Industrial Psychology, 35(1): 87-96.

Strümpfer DJW, Danana N, Gouws JF \& Viviers MR. 1998. Personality dispositions and job satisfaction. South African Journal of Psychology, 28: 92-100. 
Strümpfer DJW \& Wissing MP. 1998. Review of South African data on the Sense of Coherence Scales as a measure of fortigenesis and salutogenesis. Paper presented at the PsySSA National Congress, Durban. 12-13 June.

Tang, TL. 2007 Income and quality of life: does the love of money make a difference? Journal of Business Ethics, 72:375-393.

Verplanken B. 2004. Value congruence and job satisfaction among nurses: a human relations perspective. International Journal of Nursing Studies, 41:599-605.

World Health Organization. 2002. Constitution of the World Health Organisation. [Online] Available at: http://whqlibdoc.who.int/hist/official_records/constitution.pdf . (Accessed: 26 July 2012).

World Health Organization. 2007. Mental health: Strengthening mental health promotion. [Online] Available at: http://www.who.int/mediacentere/factsheets/fs220/en/ (Accessed: 26 July 2012) 